\title{
Deciphering the mode of action and host recognition of bacterial type III effectors
}

\author{
Selena Gimenez-Ibanez ${ }^{\mathrm{A}}$, Dagmar R. Hann ${ }^{\mathrm{B}}$ and John P. Rathjen ${ }^{\mathrm{C}, \mathrm{D}}$ \\ A Departamento de Genética Molecular de Plantas, Centro Nacional de Biotecnología-CSIC, \\ Campus Universidad Autónoma, 28049 Madrid, Spain. \\ ${ }^{B}$ Botanical Institute, University of Basel, Section of Plant Physiology, Hebelstrasse 1, \\ $\mathrm{CH}-4056$ Basel, Switzerland.

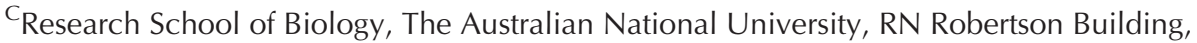 \\ Biology Place, Acton, ACT 0200, Australia. \\ ${ }^{D}$ Corresponding author. Email: john.rathjen@anu.edu.au
}

\begin{abstract}
Plant pathogenic bacteria adhere to cell walls and remain external to the cell throughout the pathogenic lifecycle, where they elicit host immunity through host plasma membrane localised receptors. To be successful pathogens, bacteria must suppress these defence responses, which they do by secreting a suite of virulence effector molecules into the host cytoplasm. However, effectors themselves can act as elicitors after perception by intracellular host immune receptors, thus, re-activating plant immunity. Bacterial effectors generally target host molecules through specific molecular activities to defeat plant defence responses. Although effectors can be used as tools to elucidate components of plant immunity, only a handful of these molecular targets are known and much remains to be learnt about effector strategies for bacterial pathogenicity. This review highlights recent advances in our understanding of the mode of action of bacterial effectors, which in the future will lead to improvements in agriculture.
\end{abstract}

Additional keywords: bacteria, defense, effector, NB-LRR, plant immunity, PRR.

\section{Introduction}

Gram-negative bacteria of the genera Pseudomonas, Xanthomonas, Ralstonia, Pantoea and Erwinia are extracellular pathogens that use a specialised type-III secretion apparatus (TTSS) to deliver virulence effector proteins into the plant cell (Jones and Dangl 2006). Collectively, these effectors manipulate host cells to optimise the pathogenic niche, particularly through suppression of the plant immune system (Jones and Dangl 2006). Plants have two sensory systems to detect pathogens; the first branch is based on extracellular recognition of highly conserved elicitors called pathogenassociated molecular patterns (PAMPs) by transmembrane pattern recognition receptors (PRRs) that typically encode receptor kinases (RKs) (Jones and Dangl 2006). Perception of PAMPs by PRRs activates PAMP-triggered immunity (PTI) and prevents further colonisation of the host (Jones and Dangl 2006). The best described examples in Arabidopsis include the recognition of the bacterial PAMPs flagellin and elongation factor-Tu (EF-Tu) by the RKs FLAGELLIN SENSING 2 (FLS2) and EF-TU RECEPTOR (EFR), respectively (GómezGómez and Boller 2000; Zipfel et al. 2006). The second sensory node operates within the cytoplasm and is triggered by specific intracellular recognition of certain effector proteins by host nucleotide binding-leucine rich repeats (NB-LRR) proteins. Activation of NB-LRR proteins results in effector-triggered immunity (ETI) and is normally accompanied by a hypersensitive cell death response (HR) at the infection site (Jones and Dangl 2006). Extracellular recognition by PRRs is generally conserved across broad taxonomic boundaries (Boller and Felix 2009), whereas intracellular recognition by NB-LRRs is typically polymorphic even within plant species (Dangl and Jones 2001). Bacterial effectors are known to suppress immune signalling events emanating from both PRRs and NB-LRRs (Nomura et al. 2006; Fu et al. 2007; Rosebrock et al. 2007; Zhang et al. 2007; Göhre and Robatzek 2008; Shan et al. 2008; Gimenez-Ibanez et al. 2009; Guo et al. 2009). However, the function and molecular host targets of most effectors remain to be elucidated. Identification of such targets is currently an important area of research in plant-pathogen interactions. The battle between plants and disease-causing pathogens has been compared with an arms race, with each innovation in host defence requiring a corresponding change in infection strategy from the pathogen, although neither entity gains the upper hand for long. This review explores emerging concepts of effector action and identification of host targets within the plant cell.

\section{The effector sets of plant pathogenic bacteria: unique combinations with highly redundant functions}

Genome sequencing has enabled annotation of the effector repertoires of five Pseudomonas syringae (P. syringae) strains, including Pto DC3000, Pto T1, P. syringae pv. syringae (Pss) B728a, P. syringae pv. phaseolicola (Pph) 1448A, and 
P. syringae pv. tabaci (Pta) 11528 (Buell et al. 2003; Feil et al. 2005; Joardar et al. 2005; Almeida et al. 2009). These possess both overlapping and distinct host ranges and represent the three major Pseudomonad pathovar clades (Sawada et al. 1999). Individual bacterial strains possess 20-30 effectors. Unexpectedly, the effector repertoires of these strains are strikingly different, even for strains such as Pto and Pss, which infect the same host (Joardar et al. 2005; Studholme et al. 2009). Thus, the composition of each effector set has so far failed to explain the host specificity of different bacterial strains, except where host recognition of effectors limits infectivity, as exemplified by the Pto DC3000 effector HopQ1-1 (Wei et al. 2007). Another general feature of effector sets is that they are collectively essential for pathogenesis but individually dispensable (Kvitko et al. 2009). Mutations that affect individual effector genes typically cause no or very subtle reductions in bacterial virulence. The reason underlying these observations is that effectors work redundantly - different effectors target the same host molecules through distinct strategies. This has been demonstrated both genetically and molecularly. Almost all effectors encoded by Pto DC3000 have the ability to suppress immune responses in at least one assay (Guo et al. 2009). Why do bacterial pathogens need such large effector repertoires with overlapping functions? First, as demonstrated experimentally, it means that individual effectors are dispensable. This allows effector loss without compromising infectivity. This may be important, for example, to allow the pathogen to discard a specific effector that is recognised by a plant NB-LRR protein without affecting its virulence, which provides an explanation for why NB-LRR mediated disease resistance in crops is often transient. Redundancy would allow an existing effector to evolve a novel or enhanced virulence function on a new host, because the original virulence activity would be retained by the redundant partner. Finally, it is possible that not all effectors are active on all plant species, so a level of redundancy is required to retain certain virulence functions on all hosts. This inbuilt redundancy makes functional analysis of effectors difficult. Thus, combinatorial effector gene deletions, or individual delivery of effectors using various experimental tools, are useful strategies to remove redundancies and identify effectors that make key contributions to disease in planta (Kvitko et al. 2009).

\section{Molecular activities of bacterial effectors}

Several detailed studies showing targeting of host molecules by bacterial type-III effectors have been published. This section summarises the most recent examples.

\section{Suppression of PAMP-triggered immunity (PTI)}

Bacteria are betrayed by PAMPs such as flagellin or EF-Tu during the early stages of infection. These molecules are sensed by PRRs, many of which rapidly form a heterocomplex with a second RK called BRI1-ASSOCIATED KINASE 1 (BAK1) shortly after elicitation (Chinchilla et al. 2007; Heese et al. 2007). Two unrelated Pto DC3000 effectors, AvrPto and AvrPtoB, interact with and inhibit the signalling of several RKs involved in PTI, including FLS2, EFR, and BAK1 (Gohre et al. 2008; Shan et al.
2008; Xiang et al. 2008; Gimenez-Ibanez et al. 2009). Different models state that AvrPto acts by directly binding and inhibiting the kinase activity of PRRs (Xiang et al. 2008), or by abrogating the formation of the FLS2-BAK1 complex required for signalling (Shan et al. 2008). These models are not mutually exclusive and remain to be resolved. In contrast to AvrPto, AvrPtoB is a multidomain protein containing a $C$-terminal E3 ubiquitin ligase domain that tags substrate proteins for subsequent degradation (Rosebrock et al. 2007; Gohre et al. 2008; Gimenez-Ibanez et al. 2009). Like AvrPto, AvrPtoB disrupted the FLS2-BAK1 complex (Shan et al. 2008), and its $N$-terminus seems to comprise a protein kinase binding domain that specifies interaction with at least five intracellular substrates (Wu et al. 2004; Rosebrock et al. 2007; Gohre et al. 2008; Shan et al. 2008; Gimenez-Ibanez et al. 2009). In addition, its E3 ligase domain is required for degradation of the PRR CHITIN ELICITOR RECEPTOR KINASE 1 (CERK1) (Gimenez-Ibanez et al. 2009) and partially degrades FLS2 (Gohre et al. 2008; Gimenez-Ibanez et al. 2009). Overall, it seems to use a bipartite strategy for suppression of kinase activity, with a variable requirement for the $C$-terminal ubiqutin ligase activity. Because both AvrPto and AvrPtoB target a commonly-used fold in plants - the RK/Pelle class of protein classes (Shiu and Bleecker 2003) - they may have many more cellular targets.

A further illustrative example concerns proteolytic cleavage of the Arabidopsis cytoplasmic kinase PBS1 by the P. syringae effector AvrPphB (Shao et al. 2003). The pathogenic strategy underlying this event was previously unclear because mutant pbs 1 Arabidopsis plants are not more susceptible to bacterial infections than wild-type plants. Recently though, Zhang and colleagues have shown that in addition to cleavage of PBS1, AvrPphB targets 10 PBS1-like (PBL) kinases, including BIK1 (BOTRYTIS-INDUCED KINASE 1), PBL1, PBL2, and PBS1 (Zhang et al. 2010). In unstimulated plants, BIK1 and PBL1 interact with FLS2 and are rapidly phosphorylated after activation of FLS2. The ligand-dependent release of BIK1 from FLS2 is in striking contrast to the previously described ligand-dependent complex formation between FLS2 and BAK1 (Chinchilla et al. 2007; Heese et al. 2007). However, the role of BIK1 in PTI is unclear because Arabidopsis mutants lacking this gene show constitutive activation of defences. Nethertheless, AvrPphB apparently inhibits PTI by cleaving PBL kinases. BIK1 and PBL1 probably integrate signalling from multiple immune receptors into downstream responses as their functions seem to be additive (Zhang et al.2010). These results raise the question of whether AvrPphB targets only those PBL kinases with roles in immunity, or lacks specificity for its substrates.

Additional strategies are used by bacterial effectors to suppress PTI downstream of PRR activation. For example, the Pto DC3000 effector HopAI1 suppresses mitogen-activated protein kinase (MAPK) activation via its phosphothreonine lyase activity (Zhang et al. 2007). MAPKs pathways transfer information from receptors to cellular responses and operate downstream of FLS2 and likely other PRRs (Asai et al. 2002; Suarez-Rodriguez et al. 2007). Despite this, He et al. (2006) previously observed neither MAPK suppression nor reductions in defence gene expression in the presence of HopAI1. Thus, the precise role of this effector in pathogenicity remains to be defined. 
Microbial perception by extra- and intra-cellular receptors orchestrates extensive reprogramming of gene transcription in favour of defence. The effector HopU1, which encodes a monoADP-ribosyltransferase (ADP-RT), suppresses plant innate immunity by modifying glycine-rich RNA-binding proteins (GR-RBPs) that possess RNA-recognition motifs (RRMs) such as GRP7 (Fu et al. 2007). Consistently, Arabidopsis plants lacking the grp7 gene are more susceptible to Pto DC3000 infection. The ADP-RT catalytic residues are required for the known defence-suppression activities of HopU1 (Fu et al. 2007). GRP7 has characteristics of an RNA binding protein, but its role(s) in plant immunity is unknown. The ADP-ribosylation of GRP7 by HopU1 may interfere with the ability of GRP7 to bind RNA. This mechanism could represent a strategy to alter RNA stability and, thus, modify the expression of a significant proportion of the plant defence transcriptome. Further work is required to discover more about the in vivo functions of the RNA-binding proteins that are ADP-ribosylated by HopU1 and their roles in plant innate immunity.

Antimicrobial compounds are thought to be secreted by exocytosis (Kalde et al. 2007). To prevent this secretion, effectors can act on proteins involved in vesicle trafficking and modify secretion of such compounds. Two effectors, HopM1 of Pto DC3000 and XopJ of Xanthomonas campestris pv. vesicatoria, interfere with this pathway (Fig. 1) (Nomura et al.
2006; Bartetzko et al. 2009). How XopJ alters vesicle trafficking is not known. In contrast, detailed analyses reveal that HopM1 exploits the plant ubiquitination system to modify vesicle trafficking. HopM1 mediates the destruction of an immunityassociated adenosine diphosphate (ADP) ribosylation factor guanine nucleotide exchange (ARF-GEF) factor named MIN7 (Arabidopsis thaliana (L.) Heynh HopM interactor 7) via the host proteasome (Nomura et al. 2006). ARF-GEFs are well known components of vesicle trafficking (Steinmann et al. 1999). AtMIN7 knockout mutants do not deposit callose into cell walls in response to flagellin treatment, and allow increased growth of the TTSS-deficient strain Pto DC3000 hrcC (Nomura et al. 2006). The MIN7 protein may be important for the accumulation of many defence-induced antimicrobial compounds at the infected site, but it is conceivable that it plays multiple roles in plant immunity, for example, biogenesis of PRRs.

It remains an open question as to why a virulent bacterium such as Pto DC3000 grows more on Arabidopsis plants lacking FLS2 when it has several effectors that are able to suppress this pathway. One possibility is that the timing of PTI elicitation relative to its effector-mediated suppression is relevant. PTI must be activated immediately upon invasion of the leaf by bacteria. In contrast, bacteria need to assemble the TTSS apparatus before secreting the effectors into the plant cell, a process that must take some hours. Thus, effectors presumably act to slow or stop active PTI

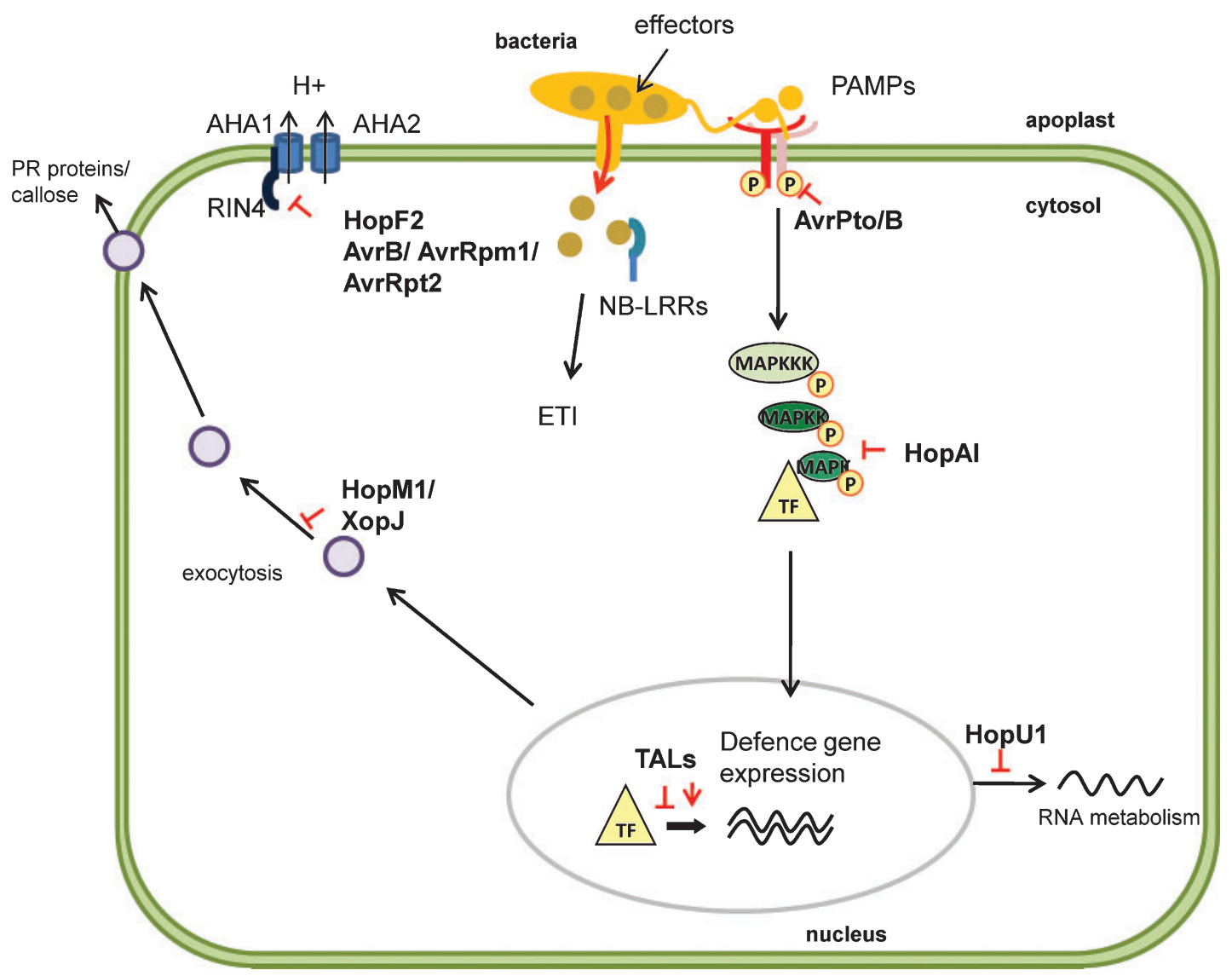

Fig. 1. Schematic diagram illustrating the various steps at which bacterial type III effectors interfere with plant innate immunity. 
signalling that has already been established. Such sequential events were previously postulated in the 'zigzag' model (Jones and Dangl 2006).

\section{Entry sites for bacterial invasion: hijacking stomata?}

Following proliferation on the leaf surface, bacteria use natural openings such as stomata to enter the plant tissue. Stomatal guard cells express PRRs that sense bacteria and induce stomatal closure, limiting bacterial access to the leaf (Melotto et al. 2006). To re-open stomata, Pseudomonas syringae pv. tomato (Pto) DC3000 produces the phytotoxin coronatine, a mimic of the phytohormone jasmonic acid (JA) (Melotto et al. 2006, 2008). However, not all Pseudomonas strains produce coronatine, raising the question of which alternative strategies are used to open stomata. Recent reports indicate that Arabidopsis RPM1INTERACTING PROTEIN 4 (RIN4) functions with the plasma membrane $\mathrm{H}^{+}$-ATPases AHA1 and AHA2 to regulate stomatal aperture (Liu et al. 2009). RIN4 is a key regulator of plant immunity, and is targeted by the type-III effectors AvrB, AvrRPM1 and AvrRpt2 (Mackey et al. 2002, 2003; Axtell and Staskawicz 2003). RIN4 is expressed in guard cells, and RIN4 overexpression and knockout lines show enhanced and reduced $\mathrm{H}^{+}$-ATPase activity respectively (Liu et al. 2009). The rin4 knockout line exhibits constitutive stomatal closure and congruently, enhanced bacterial resistance, likely by inhibiting bacterial entry to the leaf (Liu et al. 2009). It is difficult to reconcile this model with the observations that at least three Pseudomonas type-III effectors target RIN4 for destruction or modification, with the predicted outcome that this would limit virulence through stomatal closure. Recently, it was suggested that a fourth effector, HopF2, also targets RIN4, with implications for virulence (Wilton et al. 2010). It is still unclear why so many bacterial effectors target RIN4 and whether any bacterial effector truly functions in reopening stomata; one recently reported possibility is that AvrB activates mitogen activated protein kinase 4 (MPK4) via RIN4, to perturb hormone signalling and promote bacterial virulence (Cui et al. 2010). However, it has not been unequivocally demonstrated that targeting of RIN4 by effectors enhances bacterial virulence. Moreover, RIN4 targeting by the effectors AvrB, AvrRpm1 and AvrRpt2 causes activation of ETI in presence of the NB-LRRs RPS2 or RPM1, which form constitutive protein complexes with RIN4 (Mackey et al. 2002, 2003; Axtell and Staskawicz 2003). Further work could to determine whether these effectors evolved in the first instance to manipulate stomatal aperture by targeting RIN4, and whether that explains the subsequent incorporation of RIN4 into immune recognition complexes as a specificity determinant.

\section{Direct manipulation of host gene expression by TAL effectors}

The transcription activator-like (TAL) effectors of Xanthomonas spp. are important virulence factors that act in the host nucleus to manipulate gene expression (Boch et al. 2009). TAL effectors induce cell host hypertrophy and modulate disease symptomatology (White et al. 2009). A recent milestone discovery deciphered how the DNA-binding specificity of TAL effectors is encoded. All TAL effectors contain highly conserved $N$ - and $C$-terminal regions, and a variable numbers of near-identical repeats in a central repeat domain, which determines the effector's specificity (Yang et al. 2005; Boch et al. 2009; Romer et al.2009). Two hypervariable amino acids in each repeat specify one base pair in the DNA, and thus the array of repeats determines a precise DNA target sequence (Boch et al. 2009; Moscou and Bogdanove 2009; Romer et al. 2009). Remarkably, this discovery enables the prediction of the exact DNA binding site, and thus the specific genes induced by each TAL effector, with complete accuracy. Moreover, specific recognition sites for each TAL effector can be engineered upstream of suitable resistance genes to engineer protection against Xanthomonas infection. Fittingly, plants have already exploited such potential. For example, a binding sequence for the TAL effector AvrBs3 is found in the promoter region of the $B s 3$ resistance gene, resulting in conditional expression of $B s 3$ in the presence of AvrBs3 (Romer et al. 2007). Thus, in contrast to the previous examples, TAL effectors show extreme target specificity and do not seem to act redundantly because several of them are essential for virulence (Gurlebeck et al. 2006; Kay and Bonas 2009).

\section{Linking effector activities with effector-triggered immunity}

TAL effectors illustrate how bacterial effectors manipulate host gene expression to their advantage, and furthermore how the host can exploit this pathogen-driven recognition event to specify immunity. A similar situation appears to occur for Pseudomonas effectors, albeit at the level of protein-protein interactions. As discussed above, Arabidopsis RIN4 is targeted by multiple effectors and this has been exploited by the host through protein complexes with immune receptors. RIN4 forms complexes with the NB-LRR proteins RPS2 and RPM1 respectively (Mackey et al. 2002, 2003; Axtell and Staskawicz 2003). Degradation of RIN4 by AvrRpt2 activates RPS2, whereas association of AvrB or AvrRPM1 with RIN4 activates RPM1. In another example, PBL kinases such as BIK1 and PBS1 are cleaved by the cysteine protease AvrPphB to inhibit PTI (Zhang et al. 2010). However, cleavage of PBS1 is monitored by the NB-LRR protein RPS5, resulting in the activation of ETI (Shao et al. 2003). A similarly interesting scenario exists for the effectors AvrPto and AvrPtoB, which target the protein kinase domains of related RKs. In tomato, the NB-LRR protein Prf forms a constitutive complex with Pto kinase (Mucyn et al. 2006), which is closely related to the kinase domains of CERK1 and FLS2 (Gohre et al. 2008). Thus, AvrPto and AvrPtoB associate with Pto apparently because of their virulence strategy of targeting PRR kinase domains, but in this case they activate the co-evolved Pto/Prf complex. Pto and Prf form a multimeric protein complex that can contain other Pto-like kinases including Fen, Pth2, Pth3 or Pth5 (Gutierrez et al. 2010) and recent data suggest that at least one other effector in Pto DC3000 elicits the Prf complex, albeit to a lesser extent than AvrPto and AvrPtoB (Gutierrez et al. 2010). It seems highly likely that these examples will be generalised by further discoveries, although it remains to be determined how effector signals, which exert a negative effect on PTI components, can become positive activators of ETI. Interestingly, Ntoukakis and 
colleagues recently showed that Pto inactivates AvrPtoB by phosphorylating it within its E3 ligase domain (Ntoukakis et al. 2009). The deactivated AvrPtoB molecule then activates the Prf complex.

New data on cooperation between the Arabidopsis TIR-NB$L R R$ genes RPS4 and RRS1 provide an insight into multiple recognition events encoded by a single genetic locus (Birker et al. 2009; Narusaka et al. 2009). These genes are arranged in antiparallel tandem within the major recognition gene complex MRC-J on chromosome 5 (Birker et al. 2009). While it was known previously that RPS4 confers immunity to $P$. syringae through recognition of the effector AvrRps4 (Gassmann et al. 1999) and RRS1 recognises the Ralstonia solanacearum effector PopP2 (Deslandes et al. 2003), the new data show that these genes are mutually required for both of these resistance specificities, and recognition of the fungus Colletotrichum higginsianum as well (Birker et al. 2009; Narusaka et al. 2009). Double mutants in RPS4 and RRS1 are not more susceptible than single mutants, suggesting that the encoded proteins act in the same pathway, potentially as members of a protein heterocomplex. Fascinatingly, there are nine other examples of such coordinate $N B-L R R$ gene arrangement in the Arabidopsis genome (Narusaka et al. 2009) and numerous other examples of $N B-L R R$ genes working together exist. If the encoded proteins do exist within the same complex, it may be analogous to tomato Prf, which incorporates different Pto-like kinases as part of a multimeric complex to broaden its effector recognition capabilities (Gutierrez et al. 2010). Overall, the data reviewed here reveal some of the micro-evolutionary molecular events that underlie antagonistic co-evolution in the pathogen-plant host relationship.

\section{Acknowledgements}

We apologise to those authors whose work could not be cited owing to space limitations. SGI is funded by the Federation of European Biochemical Societies (FEBS). DRH is funded by the Suisse National Science foundation and the Suisse Initiative in Systems Biology (SystemsX: Plant growth in a changing environment). JPR is an Australian Research Council Future Fellow (FT0992129).

\section{References}

Almeida NF, Yan S, Lindeberg M, Studholme DJ, Schneider DJ, et al. (2009) A draft genome sequence of Pseudomonas syringae pv. tomato T1 reveals a type III effector repertoire significantly divergent from that of Pseudomonas syringae pv. tomato DC3000. Molecular Plant-Microbe Interactions 22(1), 52-62. doi:10.1094/MPMI-22-1-0052

Asai T, Tena G, Plotnikova J, Willmann MR, Chiu WL, Gomez-Gomez L, Boller T, Ausubel FM, Sheen J (2002) MAP kinase signalling cascade in Arabidopsis innate immunity. Nature 415(6875), 977-983. doi:10.1038/ $415977 \mathrm{a}$

Axtell MJ, Staskawicz B (2003) Initiation of RPS2-specified disease resistance in Arabidopsis is coupled to the AvrRpt2-directed elimination of RIN4. Cell 112, 369-377. doi:10.1016/S0092-8674(03) 00036-9

Bartetzko V, Sonnewald S, Vogel F, Hartner K, Stadler R, Hammes UZ, Bornke F (2009) The Xanthomonas campestris pv. vesicatoria type III effector protein XopJ inhibits protein secretion: evidence for interference with cell wall-associated defense responses. Molecular Plant-Microbe Interactions 22(6), 655-664. doi:10.1094/MPMI-22-6-0655
Birker D, Heidrich K, Takahara H, Narusaka M, Deslandes L, Narusaka Y, Reymond M, Parker JE, O'Connell R (2009) A locus conferring resistance to Colletotrichum higginsianum is shared by four geographically distinct Arabidopsis accessions. The Plant Journal 60(4), 602-613. doi:10.1111/ j.1365-313X.2009.03984.x

Boch J, Scholze H, Schornack S, Landgraf A, Hahn S, Kay S, Lahaye T, Nickstadt A, Bonas U (2009) Breaking the code of DNA binding specificity of TAL-type III effectors. Science 326(5959), 1509-1512. doi:10.1126/science.1178811

Boller T, Felix G (2009) A renaissance of elicitors: perception of microbeassociated molecular patterns and danger signals by pattern-recognition receptors. Annual Review of Plant Biology 60, 379-406. doi:10.1146/ annurev.arplant.57.032905.105346

Buell CR, Joardar V, Lindeberg M, Selengut J, Paulsen IT, et al. (2003) The complete genome sequence of the Arabidopsis and tomato pathogen Pseudomonas syringae pv. tomato DC3000. Proceedings of the National Academy of Sciences of the United States of America 100 (18), 10181-10186. doi:10.1073/pnas.1731982100

Chinchilla D, Zipfel C, Robatzek S, Kemmerling B, Nurnberger T, Jones JD, Felix G, Boller T (2007) A flagellin-induced complex of the receptor FLS2 and BAK1 initiates plant defence. Nature 448(7152), 497-500. doi:10.1038/nature05999

Cui H, Wang Y, Xue L, Chu J, Yan C, Fu J, Chen M, Innes RW, Zhou JM (2010) Pseudomonas syringae effector protein AvrB perturbs Arabidopsis hormone signaling by activating MAP kinase 4. Cell Host \& Microbe 7(2), 164-175. doi:10.1016/j.chom. 2010.01.009

Dang1 JL, Jones JDG (2001) Plant pathogens and integrated defence responses to infection. Nature 411, 826-833. doi:10.1038/35081161

Deslandes L, Olivier J, Peeters N, Feng DX, Khounlotham M, Boucher C, Somssich IE, Genin S, Marco Y (2003) Physical interaction between RRS1-R, a protein conferring resistance to bacterial wilt, and PopP2, a type III effector targeted to the plant nucleus. Proceedings of the National Academy of Sciences of the United States of America 100(13), 8024-8029. doi:10.1073/pnas. 1230660100

Feil H, Feil WS, Chain P, Larimer F, DiBartolo G, et al. (2005) Comparison of the complete genome sequences of Pseudomonas syringae pv. syringae B728a and pv. tomato DC3000. Proceedings of the National Academy of Sciences of the United States of America 102(31), 11064-11069. doi:10.1073/pnas.0504930102

Fu ZQ, Guo M, Jeong BR, Tian F, Elthon TE, Cerny RL, Staiger D, Alfano JR (2007) A type III effector ADP-ribosylates RNA-binding proteins and quells plant immunity. Nature 447(7142), 284-288. doi:10.1038/ nature 05737

Gassmann W, Hinsch ME, Staskawicz BJ (1999) The Arabidopsis RPS4 bacterial-resistance gene is a member of the TIR-NBS-LRR family of disease-resistance genes. The Plant Journal 20(3), 265-277. doi:10.1046/ j.1365-313X.1999.t01-1-00600.x

Gimenez-Ibanez S, Hann DR, Ntoukakis V, Petutschnig E, Lipka V, Rathjen JP (2009) AvrPtoB targets the LysM receptor kinase CERK1 to promote bacterial virulence on plants. Current Biology 19(5), 423-429. doi:10.1016/j.cub.2009.01.054

Göhre V, Robatzek S (2008) Breaking the barriers: microbial effector molecules subvert plant immunity. Annual Review of Phytopathology 46, 189-215. doi:10.1146/annurev.phyto.46.120407.110050

Gohre V, Spallek T, Haweker H, Mersmann S, Mentzel T, Boller T, de Torres M, Mansfield JW, Robatzek S (2008) Plant pattern-recognition receptor FLS2 is directed for degradation by the bacterial ubiquitin ligase AvrPtoB. Current Biology 18(23), 1824-1832. doi:10.1016/ j.cub.2008.10.063

Gómez-Gómez L, Boller T (2000) FLS2: An LRR receptor-like kinase involved in the perception of the bacterial elicitor flagellin in Arabidopsis. Molecular Cell 5(6), 1003-1011. doi:10.1016/S1097-2765 (00)80265-8 
Guo M, Tian F, Wamboldt Y, Alfano JR (2009) The majority of the type III effector inventory of Pseudomonas syringae pv. tomato DC3000 can suppress plant immunity. Molecular Plant-Microbe Interactions 22(9), 1069-1080. doi:10.1094/MPMI-22-9-1069

Gurlebeck D, Thieme F, Bonas U (2006) Type III effector proteins from the plant pathogen Xanthomonas and their role in the interaction with the host plant. Journal of Plant Physiology 163(3), 233-255. doi:10.1016/ j.jplph.2005.11.011

Gutierrez JR, Balmuth AL, Ntoukakis V, Mucyn TS, Gimenez-Ibanez S, Jones AM, Rathjen JP (2010) Prf immune complexes of tomato are oligomeric and contain multiple Pto-like kinases that diversify effector recognition. Plant Journal 61, 507-518. doi:10.1111/j.1365-313X. 2009.04078.x

He P, Shan L, Lin NC, Martin GB, Kemmerling B, Nurnberger T, Sheen J (2006) Specific bacterial suppressors of MAMP signaling upstream of MAPKKK in Arabidopsis innate immunity. Cell 125(3), 563-575. doi:10.1016/j.cell.2006.02.047

Heese A, Hann DR, Gimenez-Ibanez S, Jones AM, He K, Li J, Schroeder JI, Peck SC, Rathjen JP (2007) The receptor-like kinase SERK3/BAK1 is a central regulator of innate immunity in plants. Proceedings of the National Academy of Sciences of the United States of America 104(29), 12217-12222. doi:10.1073/pnas.0705306104

Joardar V, Lindeberg M, Jackson RW, Selengut J, Dodson R, et al. (2005) Whole-genome sequence analysis of Pseudomonas syringae pv. phaseolicola 1448A reveals divergence among pathovars in genes involved in virulence and transposition. Journal of Bacteriology 187 (18), 6488-6498. doi:10.1128/JB.187.18.6488-6498.2005

Jones JD, Dangl JL (2006) The plant immune system. Nature 444(7117), 323-329. doi: 10.1038 /nature 05286

Kalde M, Nuhse TS, Findlay K, Peck SC (2007) The syntaxin SYP132 contributes to plant resistance against bacteria and secretion of pathogenesis-related protein 1. Proceedings of the National Academy of Sciences of the United States of America 104(28), 11850-11855. doi: 10.1073/pnas.0701083104

Kay S, Bonas U (2009) How Xanthomonas type III effectors manipulate the host plant. Current Opinion in Microbiology 12(1), 37-43. doi:10.1016/ j.mib.2008.12.006

Kvitko BH, Park DH, Velasquez AC, Wei CF, Russell AB, Martin GB, Schneider DJ, Collmer A (2009) Deletions in the repertoire of Pseudomonas syringae pv. tomato DC3000 type III secretion effector genes reveal functional overlap among effectors. PLoS Pathogens 5(4), e1000388. doi:10.1371/journal.ppat.1000388

Liu J, Elmore JM, Fuglsang AT, Palmgren MG, Staskawicz BJ, Coaker G (2009) RIN4 functions with plasma membrane $\mathrm{H}^{+}$-ATPases to regulate stomatal apertures during pathogen attack. PLoS Biology 7(6), e1000139. doi:10.1371/journal.pbio.1000139

Mackey D, Holt BF, Wiig A, Dangl JL (2002) RIN4 interacts with Pseudomonas syringae type III effector molecules and is required for RPM1-mediated resistance in Arabidopsis. Cell 108(6), 743-754. doi:10.1016/S0092-8674(02)00661-X

Mackey D, Belkhadir Y, Alonso JM, Ecker JR, Dangl J (2003) Arabidopsis RIN4 is a target of the type III virulence effector AvrRpt2 and modulates RPS2-mediated resistance. Cell 112, 379-389. doi:10.1016/S0092-8674 (03)00040-0

Melotto M, Underwood W, Koczan J, Nomura K, He SY (2006) Plant stomata function in innate immunity against bacterial invasion. Cell 126(5), 969-980. doi:10.1016/j.cell.2006.06.054

Melotto M, Underwood W, He SY (2008) Role of stomata in plant innate immunity and foliar bacterial diseases. Annual Review of Phytopathology 46, 101-122. doi:10.1146/annurev.phyto.121107.104959

Moscou MJ, Bogdanove AJ (2009) A simple cipher governs DNA recognition by TAL effectors. Science 326(5959), 1501. doi:10.1126/ science. 1178817
Mucyn TS, Clemente A, Andriotis VM, Balmuth AL, Oldroyd GE, Staskawicz BJ, Rathjen JP (2006) The tomato NBARC-LRR protein Prf interacts with Pto kinase in vivo to regulate specific plant immunity. The Plant Cell 18(10), 2792-2806. doi:10.1105/tpc.106.044016

Narusaka M, Shirasu K, Noutoshi Y, Kubo Y, Shiraishi T, Iwabuchi M, Narusaka Y (2009) RRS1 and RPS4 provide a dual Resistance-gene system against fungal and bacterial pathogens. The Plant Journal $\mathbf{6 0}$ (2), 218-226. doi:10.1111/j.1365-313X.2009.03949.x

Nomura K, Debroy S, Lee YH, Pumplin N, Jones J, He SY (2006) A bacterial virulence protein suppresses host innate immunity to cause plant disease. Science 313(5784), 220-223. doi:10.1126/science.1129523

Ntoukakis V, Mucyn TS, Gimenez-Ibanez S, Chapman HC, Gutierrez JR, Balmuth AL, Jones AM, Rathjen JP (2009) Host inhibition of a bacterial virulence effector triggers immunity to infection. Science 324(5928), 784-787. doi:10.1126/science.1169430

Romer P, Hahn S, Jordan T, Strauss T, Bonas U, Lahaye T (2007) Plant pathogen recognition mediated by promoter activation of the pepper $B s 3$ resistance gene. Science 318(5850), 645-648. doi:10.1126/science. 1144958

Romer P, Recht S, Lahaye T (2009) A single plant resistance gene promoter engineered to recognize multiple TAL effectors from disparate pathogens. Proceedings of the National Academy of Sciences of the United States of America 106(48), 20526-20531. doi:10.1073/ pnas.0908812106

Rosebrock TR, Zeng L, Brady JJ, Abramovitch RB, Xiao F, Martin GB (2007) A bacterial E3 ubiquitin ligase targets a host protein kinase to disrupt plant immunity. Nature 448(7151), 370-374. doi:10.1038/nature05966

Sawada H, Suzuki F, Matsuda I, Saitou N (1999) Phylogenetic analysis of Pseudomonas syringae pathovars suggests the horizontal gene transfer of $\operatorname{argK}$ and the evolutionary stability of hrp gene cluster. Journal of Molecular Evolution 49(5), 627-644. doi:10.1007/PL00006584

Shan L, He P, Li J, Heese A, Peck SC, Nurnberger T, Martin GB, Sheen J (2008) Bacterial effectors target the common signaling partner BAK1 to disrupt multiple MAMP receptor-signaling complexes and impede plant immunity. Cell Host \& Microbe 4(1), 17-27. doi:10.1016/j.chom.2008. 05.017

Shao F, Golstein C, Ade J, Stoutemyer M, Dixon JE, Innes RW (2003) Cleavage of Arabidopsis PBS1 by a bacterial type III effector. Science 301 (5637), 1230-1233. doi:10.1126/science.1085671

Shiu SH, Bleecker AB (2003) Expansion of the receptor-like kinase/Pelle gene family and receptor-like proteins in Arabidopsis. Plant Physiology 132(2), 530-543. doi:10.1104/pp.103.021964

Steinmann T, Geldner N, Grebe M, Mangold S, Jackson CL, Paris S, Galweiler L, Palme K, Jurgens G (1999) Coordinated polar localization of auxin efflux carrier PIN1 by GNOM ARF GEF. Science 286(5438), 316-318. doi:10.1126/science.286.5438.316

Studholme DJ, Ibanez SG, MacLean D, Dangl JL, Chang JH, Rathjen JP (2009) A draft genome sequence and functional screen reveals the repertoire of type III secreted proteins of Pseudomonas syringae pathovar tabaci 11528. BMC Genomics 10, 395. doi:10.1186/14712164-10-395

Suarez-Rodriguez MC, Adams-Phillips L, Liu Y, Wang H, Su SH, Jester PJ, Zhang S, Bent AF, Krysan PJ (2007) MEKK1 is required for flg22induced MPK4 activation in Arabidopsis plants. Plant Physiology 143(2), 661-669. doi:10.1104/pp.106.091389

Wei CF, Kvitko BH, Shimizu R, Crabill E, Alfano JR, Lin NC, Martin GB, Huang HC, Collmer A (2007) A Pseudomonas syringae pv. tomato DC3000 mutant lacking the type III effector HopQ1-1 is able to cause disease in the model plant Nicotiana benthamiana. The Plant Journal 51 (1), 32-46. doi:10.1111/j.1365-313X.2007.03126.x

White FF, Potnis N, Jones JB, Koebnik R (2009) The type III effectors of Xanthomonas. Molecular Plant Pathology 10(6), 749-766. doi:10.1111/ j.1364-3703.2009.00590.x 
Wilton M, Subramaniam R, Elmore J, Felsensteiner C, Coaker G, Desveaux D (2010) The type III effector HopF2 Pto $_{\text {torgets }}$ Arabidopsis $\mathrm{RIN}_{4}$ protein to promote Pseudomonas syringae virulence. Proceedings of the National Academy of Sciences of the United States of America 107(5), 2349-2354. doi:10.1073/pnas.0904739107

Wu A-J, Andriotis VME, Durrant MC, Rathjen JP (2004) A patch of surfaceexposed residues mediates negative regulation of immune signaling by tomato Pto kinase. The Plant Cell 16(10), 2809-2821. doi:10.1105/tpc. 104.024141

Xiang T, Zong N, Zou Y, Wu Y, Zhang J, et al. (2008) Pseudomonas syringae effector AvrPto blocks innate immunity by targeting receptor kinases. Current Biology 18(1), 74-80. doi:10.1016/j.cub.2007.12.020

Yang B, Sugio A, White FF (2005) Avoidance of host recognition by alterations in the repetitive and $C$-terminal regions of AvrXa7, a type III effector of Xanthomonas oryzae pv. oryzae. Molecular Plant-Microbe Interactions 18(2), 142-149. doi:10.1094/MPMI-18-0142
Zhang J, Shao F, Li Y, Cui H, Chen L, et al. (2007) A Pseudomonas syringae effector inactivates MAPKs to suppress PAMP-induced immunity in plants. Cell Host \& Microbe 1(3), 175-185. doi:10.1016/j.chom.2007. 03.006

Zhang J, Li W, Xiang T, Liu Z, Laluk K, et al. (2010) Receptor-like cytoplasmic kinases integrate signaling from multiple plant immune receptors and are targeted by a Pseudomonas syringae effector. Cell Host \& Microbe 7(4), 290-301. doi:10.1016/j.chom.2010.03.007

Zipfel C, Kunze G, Chinchilla D, Caniard A, Jones J, Boller T, Felix G (2006) Perception of the bacterial PAMP EF-Tu by the receptor EFR restricts Agrobacterium-mediated transformation. Cell 125, 749-760. doi:10.1016/j.cell.2006.03.037

Manuscript received 16 April 2010, accepted 8 July 2010 